LBL --28690

DE91 004116

\title{
AN EXPERIMENT WITH DEPRESSURIZATION TESTS AS INDICATORS OF RADON AVAILABILITY IN 6 NEW JERSEY HOUSES
}

A.J. Gadgil, J.S. Najita, K.L. Revzan, J. Harrison, B.H. Turk, and W.J. Fisk

\author{
Indoor Environment Program \\ Applied Science Division \\ Lawrence Berkeley Laboratory \\ 1 Cyclotron Road \\ Berkeley, CA 94720
}

July 1990

This work was sponsored by the Assistant Secretary of Conservation and Renewable Energy, Office of Building and Community Systems Division, and by the Director, Office of Energy Research, Office of Health and Environment Research, Human Health and assessments Divis:on and Pollutant Characterization and Safety Research Division of the U.S. Department of Energy (DOE) under Contract No.DE-AC03-76SF00098. It was also supported by the U.S. Environmental Protection Agency (EPA) through Interagency Agreement DW89932609-01-0 with DOE.

\section{MASTFR}




\title{
An Experiment with Depressurization Tests as Indicators of Radon Availability in 6 New Jersey Houses
}

\author{
A.J. Gadgil, J.S. Najita, K.L. Revzan, J. Harrison", B.H. Turk**, and W.J. Fisk, \\ Indoor Environment Program, LBL
}

\begin{abstract}
ABSTR.ACT
This note describes an analysis of data from short-term (2 hours to 6 days) monitoring of indoor radon concentrations and other related parameters in six New Jersey houses before and during application of depressurization with blower doors. We examine the data for consistency, and analyze them to assess the usefulness of this short term test for identifying houses that could expose their occupants to high levels of indoor radon. The analysis shows that the short term testing of houses with application of depressurization with blower doors may have the potential of being developed into a useful screening technique. However, the data from the present experiments do not conclusively demonstrate this potential. More careful experimental tests are needed for this purpose. Recommendations are made for improving future experiments.
\end{abstract}

* Present address: Office of Radiation Programs, U.S. EPA, Washington D.C.

* Fresent address: 105 E. Marcy St., Rm 100, Santa Fe, NM 87501 


\title{
An Experiment with Depressurization Tests as Indicators of Radon Availability in 6 New Jersey Houses
}

\author{
A.J. Gadgil, J.S. Najita, K.L. Revzan, J. Harrison ", B.H. Turk ${ }^{*}$, and W.J. Fisk, \\ Indoor Environment Program, LBL
}

\section{Introduction}

Long term exposure to radon may constitute the highest single health risk to individuals from indoor air pollution in residences. Therefore the need to identify houses that expose their occupants to high long term radon concentrations has gained increasing attention in recent years. The standard means of such identification are based on either a short term (2-7 d) sampling of indoor air (e.g. with a charcoal cannister), or a long term (30 d or longer) measurement of indoor radon concentrations with alpha track detectors.

Each of these methods has its disadvantages; the short term samples have not been shown to be good indicators of long term average radon concentrations, and the alpha track detectors require a long exposure (of the order of several months) ${ }^{+}$and thus do not allow rapid assessment. A rapid screening or diagnostic technique is needed that provides a more reliable estimate of average radon exposures in the house.

Pressure driven flow of radon bearing soil gas is the predominant source of radon in houses with elevated concentrations [Nazaroff and Nero, 1988]. It is therefore possible, in principle, to simulate "worst case" conditions in a house regardless of season, employing mechanical depiessurization of the house to simulate natural basement pressure conditions found in winter. In practice, however, one expects that some of the factors that may affect indoor radon levels, such as soil moisture and temperature conditions, will change seasonally and may impair the predictive ability of the test.

In this note, we analyze results from this cxperimental method of radon testing as applied to six New Jersey houses. The houses were extensively instrumented and data collected before and during application of controlled depressurization with blower doors for short periods. The resulting changes in the indoor radon concentrations, and several other parameters were monitored. Our primary objective was to compare the indoor radon concentrations or radon entry rates stimulated by the mechanical depressurization, with those observed in these same houses under natural winter.time conditions. This would allow us to assess the suicability of this short term diagnostic test, carried out at any time of the year, as a basis for predicting the time-averaged indoor radon

\footnotetext{
- Present address: Office of Radiation Programs, U.S. EPA, Washington D.C.

** Present address: 105 E. Marcy St., Rrn 109, Santa Fe, NM 87501

An exposure of alpha track detectors to $30 \mathrm{pCi-day/l}$ of radon concentration is needed to obtain estimates with measurement errors of less than $20 \%$.
} 
concentrations in winter occurring under natural depressurization.

\section{House Characteristics}

The six houses had basements with hollow-core concrete block walls. In some houses, the walls were terminated on the top with solid concrete blocks. The frame walls of the house were supported on wooden sill plates that rested on the top of the basement walls. The hollow-core walls in the basements provided multiple pathways for the soil gas to enter the house. These were difficult to characterize: soil gas could not only enter the basement through the porous material of the walls, but could also be channeled through the hollow connected spaces inside the blocks, and cracks and openings in the blocks, to the basement interior. Once in the basement, the radon could be transported into the living space via the openings commonly found in the basement ceiling or by the air distribution sy'stem of the forced air furnace during winter heating months.

At least in some houses, the internal partition walls and flue chases probably provided a channel for air from the attic to come into the basement and the living space when the house was depressurized with a blower door. This further complicates the analysis of data taken under these conditions.

\section{Experimental Procedure and Limitations}

This work was part of an intensive study of radon entry and control in seven NJ houses. These houses were monitored under ordinary conditions for almost one year (in 1987). Several relevant variables (e.g. radon concentrations in the living space and the basement, wind speed and direction, pressures at various points, and temperatures of indoor, outdoor air, and soil) were recorded at $30 \mathrm{~min}$ intervals. These long term data form a background for this study. Some of the data have been used as the input for a model of indoor radon concentrations [Revzan 89]; additional analysis of the long term data are described in Turk et al [1988, 1989].

The short term tests were aimed at measuring the time-dependent radon entry rates and indoor radon concentrations in response to controlled depressurization.

A blower door continuously depressurized the entire house (or in some instances, only the basement) by a controlled amount, usually to about -10 pascal (Pa). The depressurization was calculated as the average of the pressure differences between the house interior and three or four outdoor points on different sides of the house. The data from continuous radon monitors (CRMs) were collected at 5 minute intervals during these tests. The short term data were collected for periods ranging from 2 hours (houses LBL-09, -11, -12, and -14) to 6 days (house LBL-13) in June 1987.

Before starting each short-term depressurization experiment, all exterior doors and windows of the house were opened, and the house flushed with outside air for 15 minutes using the blower door. This was intended to remove all pre-existing radon in the house. However, the flushing process also pressurized the house to about $10 \mathrm{~Pa}$ for that period. During the subsequent depressurization tests, the radon concentrations were monitored with CRMs at the following points: a single point at mid-height above the approximate center of the basement floor, a single point at mid-height airove the approximate center of the first-floor living room, and at one location below the slab. The 
air in the basement and the living room was, however, not well mixed with fans. It is likely that during the depressurization, air infiltrated into the house from different locations, and exited through the blower door before complete mixing. Thus the CRM readings taken at the central single point in the space may not correctly represent the average concentration of radon in the space being monitored. Similarly, the radon concentrations measured at a single point under the slab may not represent the average concentration of radon in the soil-gas entering the basement. This is particularly true because of the hollow concrete block walls that generally would allow entry to soil gas bearing less radon than that from under the slab.

Rain fell intermittently during some of the tests. This rain would increase the saturation of the top layer of the soil. The magnitude of the increase, (and its effect) would depend on the intensity and duration of the rainfall, the initial soil moisture content, the soil permeability, and other physical characteristics (e.g. the der, ree of drainage at the site).

\section{Analysis Objectives}

This analysis had the following objectives:

a) Examine the data and try to interpret it in ierms of a model that relates the observed radon concentrations to house characteristics and other measured causative factors.

b) Compare the concentrations or radon entry rates during the test period with those during winter. Examine if the short term tests could serve as diagnostic tools to identify houses with high radon winter concentrations.

\section{Analysis Method and Results.}

Since the data were logged at 5 minute intervals, much shorter than the equilibrium time of CRMs (which is about 100 minutes), all CRM count rates were processed using a dynamic analysis [Busigin et al 1979]. Software for processing the count rate data using this procedure was adapted from Bonnefous [Bonnefous 1989].

First we consider the effect of the initial pressurization of the house to about $10 \mathrm{~Pa}$ for 15 minutes in terms of its interference with the interpretation of data from the depressurization experiments. The measurements of soil permeability adjacent to the houses yield values of the order of 0.5 Darcy. At these values, assuming homogeneous soils (e.g. no exceptionally high permeability pathways for air from the sub-slab region to exposed ground surface), we calculate that the sub-slab soil will not be flushed of radon bearing soil gas during the 15 minute initial pressurization. On the other hand, presence of a sub-slab gravel layer (typical thickness $10 \mathrm{~cm}$, porosity 0.4 ) would dilute the radon concentration in the soil gas held in the gravel layer by about $5 \%$, assuming complete mixing. Thus in either case, the small amount of basement air that enters the sub-slab region during the initial pressurization would not significantly affect test results obtained well after the first 15 minutes of depressurization.

We examined if it is possible to analyze the radon concentration data for a fraction of the test duration for a house, and use it to extract some model parameters that would allow us to predict the radon concentration for the rest of the test duration for that house. The radon concentration in the basement, under conditions of complete mixing 
and steady state rates of ventilation and radon entry, is obtained from basic massbalance considerations as:

$$
C(t)=C_{0}\left(e^{-Q T}\right)+\frac{S}{Q V}\left(1-e^{-Q T}\right)
$$

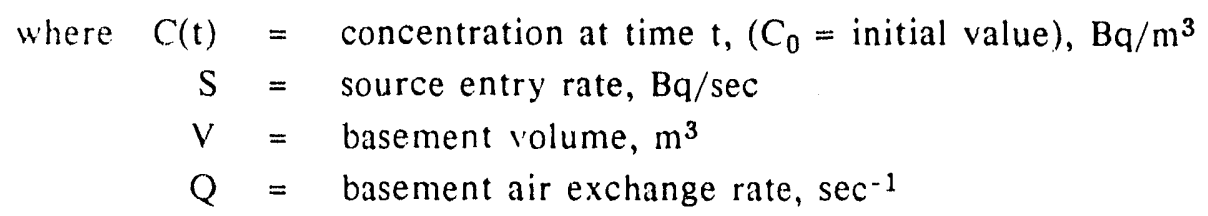

l'hi- xpression assumes that the air entering the basement (except as soil gas) has a negligible radon concentration, and that $S$ and $Q$ are constant after depressurization.

For this analysis, we selected a segment of data that showed relatively steady levels of sub-slab radon concentration. An exponential was fitted to the rising concentration of basement radon at the initiation of the depressurization, using the measured concentrations of radon at the beginning of and well into the depressurization, and adjusting the ventilation rate as a free parameter. A fit to the data for house LBL-13 is shown in Fig. 1. The basement ventilation rate (under depressurized conditions) found from the fit is 1.6 air changes per hour $(\mathrm{ACH})$.

We found that a quasi-steady-state analysis using the above equation over small time intervals is not able to predict the basement radon concentrations. This is true even if one uses, as an input to the analysis, the measured (and variable) radon concentration at the sub-slab point.

We first briefly describe the expected time-dependence of radon concentrations in the sub-slab soil gas and in a well mixed basement, for a basement sited in homogeneous soil and subjected to a sudden increase in depressurization. This description is relevant for interpretation of the observed time dependence of radon concentrations in sub-slab soil gas and the basements in these experiments. For a sudden onset of a small and steady depressurization of a basement, one expects that the basement radon concentration would first rise rapidly, and then more and more slowly until it asymptotically approaches a higher steady-state value. For depressurization with only a few $\mathrm{Pa}$, one expects the subslab radon concentration to not change significantly. On the other hand, if the depressurization is large, the transit time of air, as it enters the ground surface and travels through the soil to the basement, may be so shortened that it becomes comparable to the mean life of radon atoms. In that case, the subslab radon concentration will remain steady for a while after the onset of depressurization, but will then decline, as fresher, less radon-laden soil gas reaches the sub slab points. Similarly, the radon concentration in the basement will first rise towards a higher steady-state value, and then slightly decline, as the radon concentration in the soil gas entering the basement declines to a value lower than at the onset of the experiment. For almost all soils, and for commonly found basement geometries, the time scale for the rise of basement radon concentration is expected to be much shorter than the time scale for the decline in the radon concentration in the sub-slab soil gas. Nazaroff and Sextro [1989] give a more detailed exposition of the analyses. However, as the data in Figs. 2 - 5 show, the radon concentrations at the sub-slab location (and in the basement and the living area), do not 
always follow the expected changes with changes in depressurization.

This brings us to one of the points on which the present analysis approach flounders: the measured sub-slab radon concentrations often vary strongly in a puzzling manner. Unless the analysis (and the experimental technique) are capable of predicting the large variation in radon entry rate (which is a product of the sub-slab radon concentration and the soil gas entry rate), one would not be able to predict reliably the indoor long term concentrations in winter. Similar short-term variation was observed in the sub-slab radon concentrations (measured at $30 \mathrm{~min}$ intervals) over a period of several months. Such variation is an indication that there are ill-understood mechanisms supplying radon at the sub-slab point, perhaps fissures or cracks, or highly permeable strata allowing long range transport of radon to the sub-slab point. Changes in atmospheric pressure can possibly affect the motion of soil-gas and lead to such changes in sub-slab radon concentration. This uffect, sometimes called "atmospheric pumping" refers to changes in the velocity of soil gas flow in the region near the basement, caused by the random fluctuations in atmospheric pressure. These fluctuations can be of the order of $50 \mathrm{~Pa}$ over periods of 30 minutes [Narasimhan et al, 1990]. Another possible mechanism contributing to variation in the sub-slab radon concentration would be the interaction of wind with an exposed high permeability stratum of soil that connects the soil surface to a point below the basement slab. The fluctuating wind pressure at the ground level surface of the stratum could result in fluctuating amounts of radon-rich soil gas being driven to the sub-slab point.

The resistance to the pressure driven flow of soil gas into the basement consists of two contributions: that from the soil-block surrounding the basement, and that from the basement shell itself (e.g. from the cracks in the slab). The ratio of these two resistances equals the ratio of pressure differences across them; one difference measured just across the basement slab, and the other between a point inside the basement and a point far away from the house, inside the soil, (with both points at the basement floor level). This latter ratio can be calculated from experimental measurements. If one assumes that the resistance offered by the basement shell is constant, the temporal variations in this ratio provide secondary information on the temporal variations in the effective combined permeability of sub-slab aggregate and the soil surrounding the basement. We examined the correlation between this ratio, obtained from the long term data for LBL-13, and LBL-10, and the sub-slab radon concentrations. No relationship was found (correlation coefficients of 0.20 and 0.02 respectively). Therefore we believe that the variations in the soil and aggregate permeability did not play a significant role in causing the large variations in sub-slab radon concentrations. This of course does not rule out the roles of the mechanisms mentioned in the previous paragraph in causing the observed variations in the sub-slab radon concentrations.

House LBL-10 was sited on low permeability clay, but with a layer of high permeability disturbed soil around the house and below the basement. This high permeability layer probably allowed a large rate of soil gas entry into the house, according to nodel predictions for such configurations [Revzan and Fisk, 1990). We explored the possibility that the radon concentrations in this high permeability layer changed sharply partly owing to wind-induced pressure driven flow through it, and this caused the large variations in the sub-slab radon concentrations, (Fig. 3). However, we did not find evidence of any clear link between the wind speed and the sub-slab radon concentrations for 


\section{LBL-10.}

Increases in soil saturation (owing to intermittent rain) can sharply reduce the relative permeability of soil, strongly affecting the rate of transport of soil gas (and radon) into the house even when the depressurization is maintained constant. Thirty-minute records of rainfall data were examined; however, the analysis yielded no useful relationship linking the soil-gas entry rate to the rainfall.

An alternative to detailed modeling of the mechanism of radon entry, is to look for a simple proportionality between the radon levels observed during depressurization to those observed during winter. However, the proportionality factor may have to be modified by a correction term to take into account seasonal variables (e.g. soil permeability) to provide a reasonable estimate of long term average radon concentrations.

Soil perneability data were collected weekly for ieveral months, at several points around each house. There is some variation in the soil permeability from week to week, the ratio of the largest to the smallest values recorded for a given location being of the order of 2, diring the period from August to September. No data were recorded for mid-winter weeks (November through January), so a comparison of mid-winter and test-date values is not possible. Variation in soil permeability of the order of 2 is within experimental reproducibility. Since the variation is not significantly outside the range of experimentai error, the correction factor can be set to 1 .

During the test period itself, the ratio of pressure difference across the basement slab to that between the basement's interior and a distant point in the soil, did not vary much. For example, for LBL-13 this ratio varied modestly between 0.4 and 0.2 over the six-day test period. This suggests that integrated over the different paths of soil-gas, the soil permeability did not vary much during the test period, in spite of the intermittent rain. An examination of the limited data on monthly soil permeability from the vicinity of the test houses also shows permeability values during the test period to be close to those measured during the long term test period.

For the last 8 hours of the test on LBL-13, the blower door was moved from the living room patio to the basement entrance. Recall that the depressurization was maintained constant, as measured by the average pressure difference between the basement and four exterior pointe on different sides of the house. This averaging was performed to obtain a constant depressurization not affected by pressure variations induced by the interartion of the wind with the building. From an examination of the wind speed data, and the data from the four pressure difference sensors, we conclude that there were no over-riding effects of high wind speeds that would lead to large wind-induced variations in the ventilation rate. If, as a result, the basement ventilation rate and the soil-gas entry rate (owing to constant depressurization) can be presumed to be more or less constant over this 8-hour period, almost all the variation in the radon concentration in the blower door exhaust should be accounted for by the variation in the radon concentration of soil-gas entering the basement. This is conceptually straight forward, but could not be verified with the data that we examined. We found poor correlation ( $R$ of 0.3 ) between the sub-slab radon concentration and the blower door exhaust radon concentration for these 8 hours. The transport of fresh air into the depressurized basement from the attic via partition walls and flue chases (this flow could be variable with fluctuating wind, and the variation remain undetected by the four pressure difference senso's), as well as the poor mixing of radon in the basement air, may be implicated; ihese 
mechanisms may have led to data for basement radon conceitiations that are not a useful measure of radon entry rates in the basement.

Lastly, as a simplistic measure of predictive ability of the present tests, (without attempting to formulate any model to interpret the data and extend it to winter conditions), we looked for a correlation between the values of volume-averaged indoor radon concentrations (during the end of the periods of depressurization, when indoor concentrations are more stable), with time-averaged and volume-averaged radon concentrations measured (during the long term monitoring) in the heated zones during winter. (Since the mixing rates of basement air with living zone air are different during winter and short term depressurization tests, only a volume-weighted average can be expected to yield reasonable results). A correlition coefficient, $\mathrm{R}$, of 0.73 is obtained, (Fig. 6). An examination of this figure also shows that the single data point contributed by house LBL-13 may contribute substantially to the appearance of a correlation. This is confirmed when the correlation obtained by excluding this data point turns out to have an $\mathrm{R}$ of 0.48 . Since the radon concentration is only weakly dependent on the level of depressurization (recall that with increasing depressurization the rates of radon entry as well as that of its removal by ventilation, both increase, although not in proportion), a. correlation of winter volume-averaged house radon concentrations with that during depressurization on a per pascal basis, leads to a somewhat poorer correlation coefficient, $R=0.66$, (Fig. 7). Excluding the data point contributed by house LBL-13 lowers the correlation dramatically to $\mathrm{R}$ of 0.16

\section{Suggestions for Future Work}

Additional efforts are needed to experimentally test the predictive ability of this method of short term screening for radon. However, these efforts should be undertaken with care. We suggest the following points for consideration in the design of future experiments:

1) The experiments should be undertaken initially with houses having potentially fewer complications than those in the present study, regarding flow and leakage pathways for air and soil-gas entry. Houses with basements having poured concrete walls would be preferable to those with hollow-core block walls. Or as an even simpler approcich, initial experiments can be conducted on slab-on-grade houses without basements, and without any combustion appliances vented directly to the outdoors. Mixing fans should be operated in all the indoor spaces where radon concentrations are being monitored.

2) Data analysis should proceed concurrently with experiments so that problems in data collection, inaciequacies in the number of data channels, methodological weaknesses, etc., are identified and rectified during the experiment. The field study schedule should allow for the necessary time for iterations between the data

\footnotetext{
* For some houses that had two stories, the winter radon concentrations upstairs were not measured - we assumed that these were the same as those measured on the first floor, since both levels were supplied with heated air from a basement furnace. On the other hand, we assumed zero radon concentrations on the second level during the depressurization tests, because there was no identifiable mechanism during the tests that would transport the radon to the second story.
} 
analysis and the instrument modifications and collection of more data, until the data collection and analysis are satisfactorily concluded. For example, the main stumbling blocks in the present analysis (the large unexplained variations in subslab radon concentrations, and the poor mixing of air in the basement space leading to CRM data that may not represent basement radon entry rates) could have been addressed if we had more time and personnel to concurrently schedule preliminary data analysis. Other experinentai lacunae may exist, and would be identified and eliminated by the iterations between analysis and data collection.

3) 'It is perhaps desirable to "overinstrument" one or two houses, (with thorough instrumentation for the analysis of all air and soil-gas entry and removal mechanisms), before widening the scope of the study to include more houses, and houses with more complex pathways. In such a study, one would plan the instrumentation with some redundancy (e.g. monitoring subslab rartnn concentrations at multiple points).

4) The houses should be tested at several levels of depressurization. The lower magnitudes are closer to the depressurization that occurs in natural settings, but the tests at higher depressurization have less interference from naiurally caused pressure changes.

\section{Concluding Remarks}

The present data do not strongly support the predictive ability of this technique for screening for high radon houses. This is perhaps understandable given that this is the first time that depressurization with blower doors was experimented with as a short term screening test. The houses on which it was tried turned out to be surprisingly complex, and the experimental methods did not prove extensive enough to unravel all the unanticipated complexities.

The empirical correlation obtained between the radon concentrations during the short term tests and those during winter is encouraging. The results, based on a limited sample of $6 \mathrm{New}$ Jersey houses, indicate that a house with high levels of indoor rarlon in winter would also have elevated levels during depressurization. The technique may have practical use if developed further and validated by testing on a larger sample of houses under a broader range of soil types and winter radon levels.

\section{Acknowledgements}

We gratefully ackrou ledge thoughtful guidance and critique from our colleagues, $A$. V. Nero, R. G. Sextro, and M. P. Modera, all of LBL.

This work was sponsored by the Assistant Secretary for Conservation and Renewable Energy, Office of Building and Community Systems Division, and by the Director, Office of Energy Research, Office of Health and Environment Research, Human Health and Assessments Division and Pollutant Characterization and Safety Research Division of the U.S. Department of Energy (DOE) under Contract No. DE-AC03-76SFOOO98. It was also supported by the U.S. Environmental Protection Agency (EPA) through Interagency Agreement DW89932609-01-0 with DOE. Although the research described lare is partially supported by the EPA, it has not been subjected to EPA review and therefore does not necessarily refect the views of EPA, and no official endrsement by 
EPA should be inferred.

\section{References}

1. Nazaroff, W.W., and Nero, A.V. (eds), "Radon, and its Decay Products in Indoor Air", John Wiley and Sons, New York, 1988.

2. Revzan, K.L. (1989) "Radon Entry, Distribution, and Removal in Two New Jersey Houses with Basements". Submitted to Health Physics. Lawrence Berkeley Laboratory Report, LBL-26830, April, 1989.

3. Turk, B.H., Harrison, J., and Sextro, R.G. (1989) "Performance of Radon Control Systems", submitted to Energy and Buildings. Law rence Berkeley Laboratory Report, LBL-27520, June 1989.

4. Turk, B.H., Harrison, J., Sextro, R.G., Hubbard, L.M., Gadsby, K.J., Matthews, T.G., Dudney, C.S., and Sanchez, D.C., "Evaluation of Radon Reduction Techniques in Fourteen Basement Houses: Preliminary Result", in Proceedings of the 81st Annual Meteting of ihe Air Pollution Control Association, Dalias, TX, Paper No. 88-107.2, APCA, Pittsburgh, PA, 1988.

5. Nazaroff, W.W., and Sextro, R.G., "Technique for Measuring the Indoor ${ }^{222} \mathrm{Rn}$ Source Potential of the Soil", Environmental Science and Technology, Vol. 23, pp. 451-458, (1989).

6. Busigin, A., Van der Vooren, A., and Phillips, C., "Interpretation of the Response of Continuous Radon Monitors to Transient Radon Concentrations", Health Physics, Vol. 37, pp. 659-667, 1979.

7. Bonnefous, Y.C., "Le Radon dans l'habitat: mesure en cotinu de la concentration en radon". Master's Thesis, at I.N.S.A. de Lyon, Laboratory : L.A.S.H.- Ecole Nationale des Travaux Publics, September 1989.

8. Fisk, W.J., and Mowris, R.J., "The Impacts of Balanced and Exhaust Ventilation on Indoor Radon", in Indoor Air '87 eds. Seifert, B., Esdorn, H., Fischer, M., Ruden, H., and Wenger, J., Vol. 2, pp. 316-320, Institute for Water, Soil, and Air Hygiene, Berlin, West Germany, 1987.

9. Revzan, K.L., and Fisk, W.J., "Modeling Radon Entry into Houses with Basements: The Influence of Structural Factors ", Lawrence Berkeley Laboratory Report, LBL,-28109, December 1989.

10. Narasimhan, T.N., Tsang, Y.W., and Holman, H.Y., "On the Potential Importance of Transient Air Flow in Advective Radon Entry into Buildings", Geophysical Research Letters, 'ol. 17, No. 6, pp. 821-824, (May 1990). 


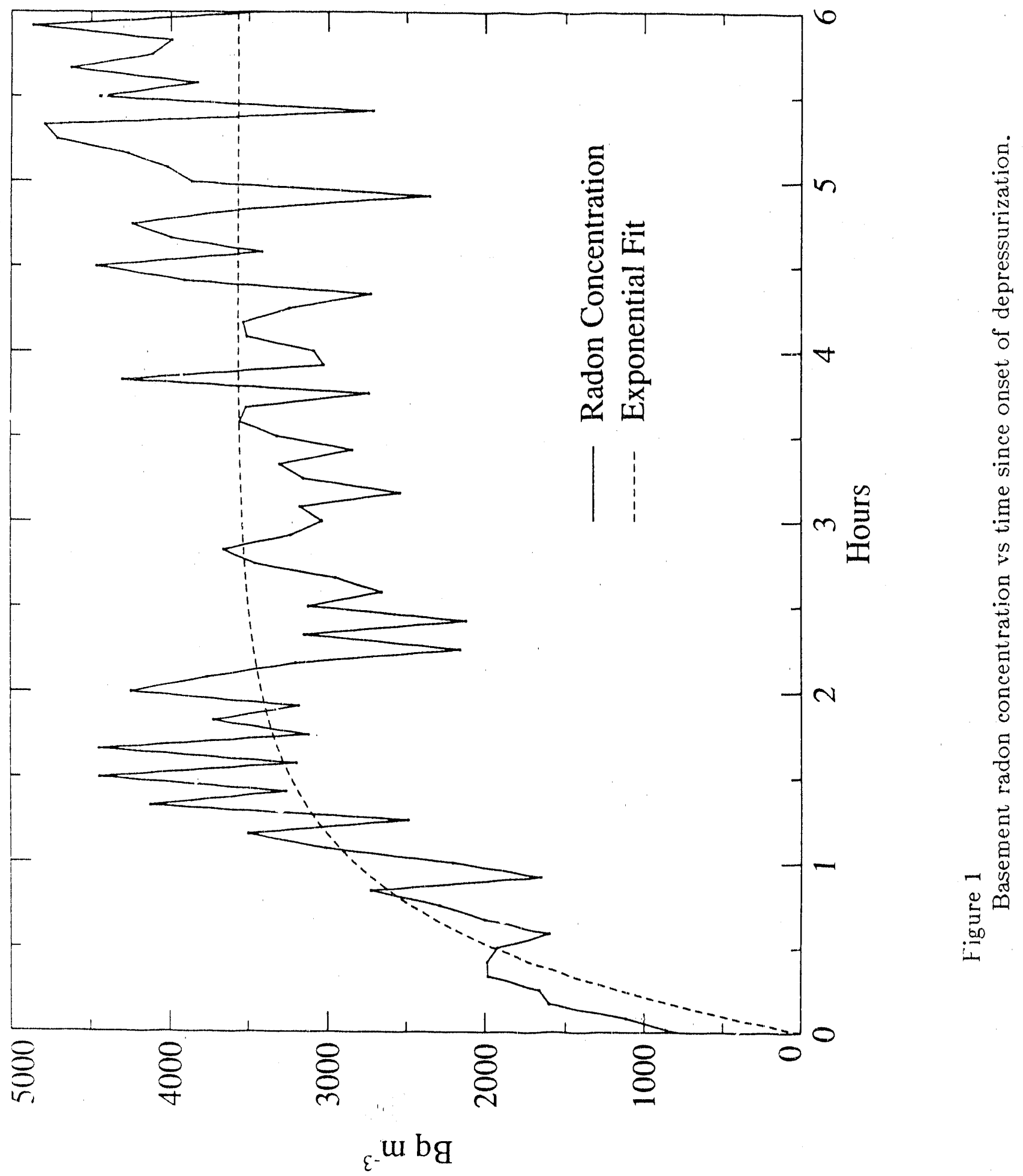




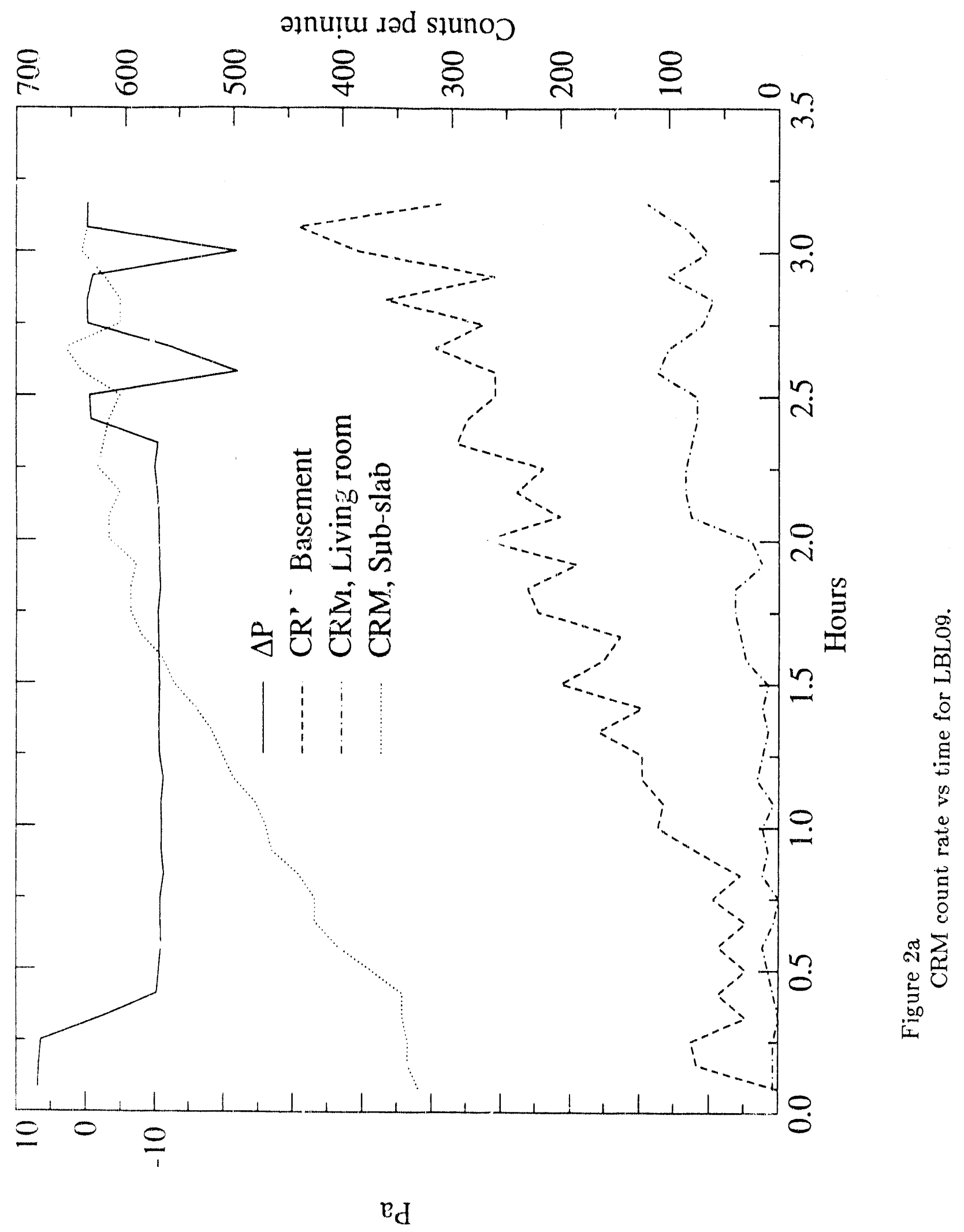




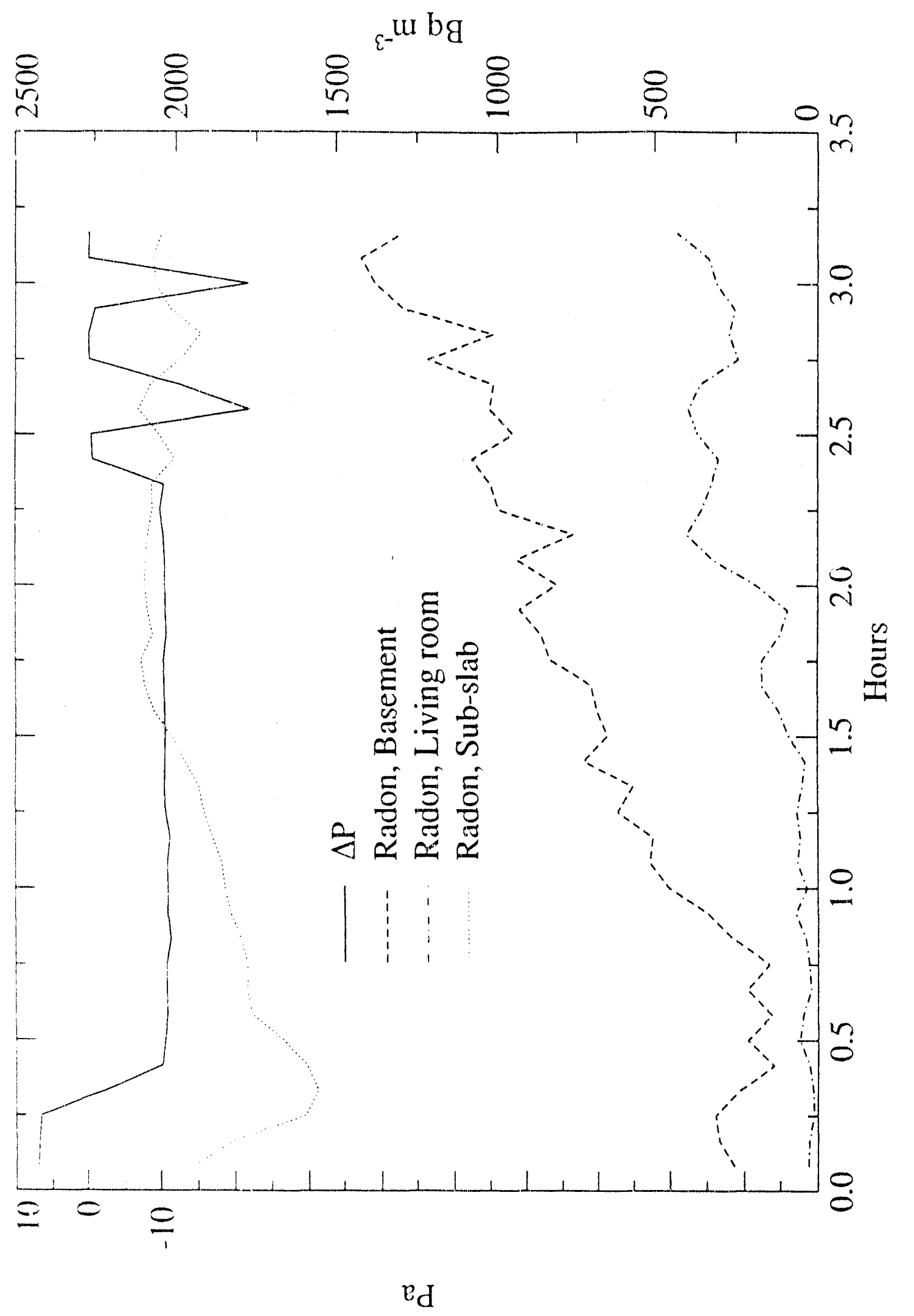

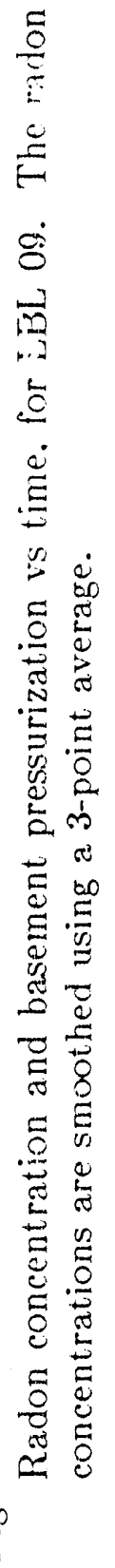




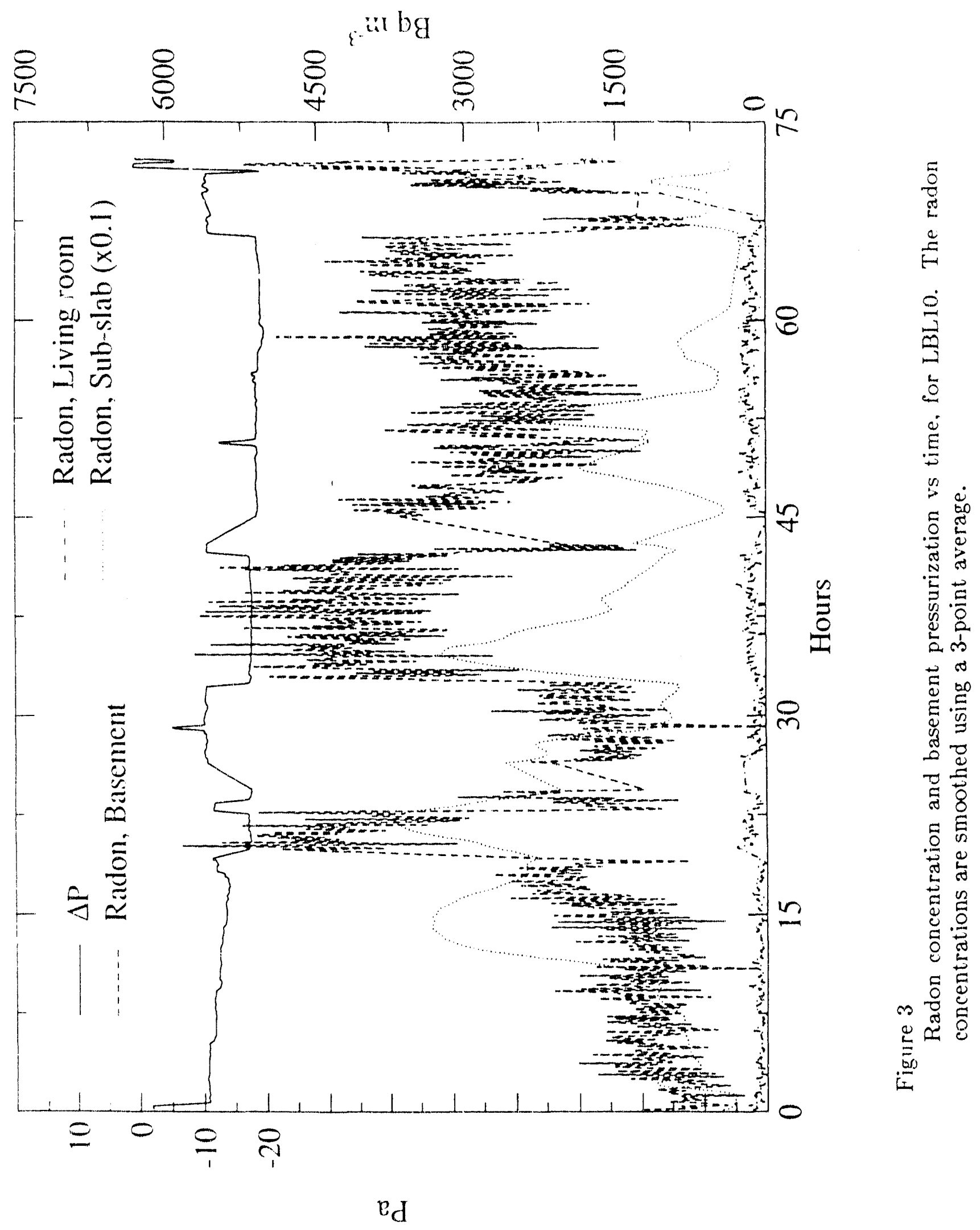



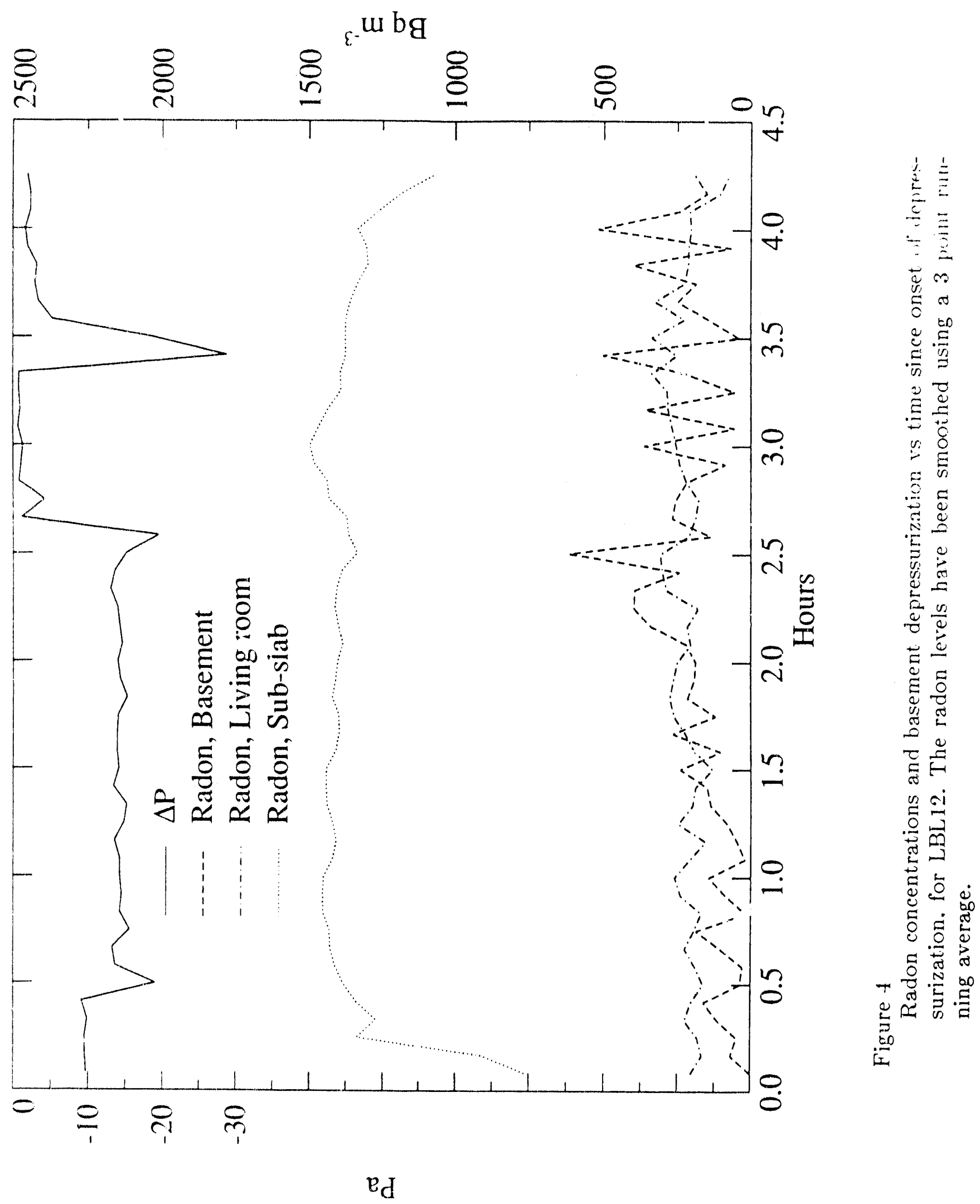


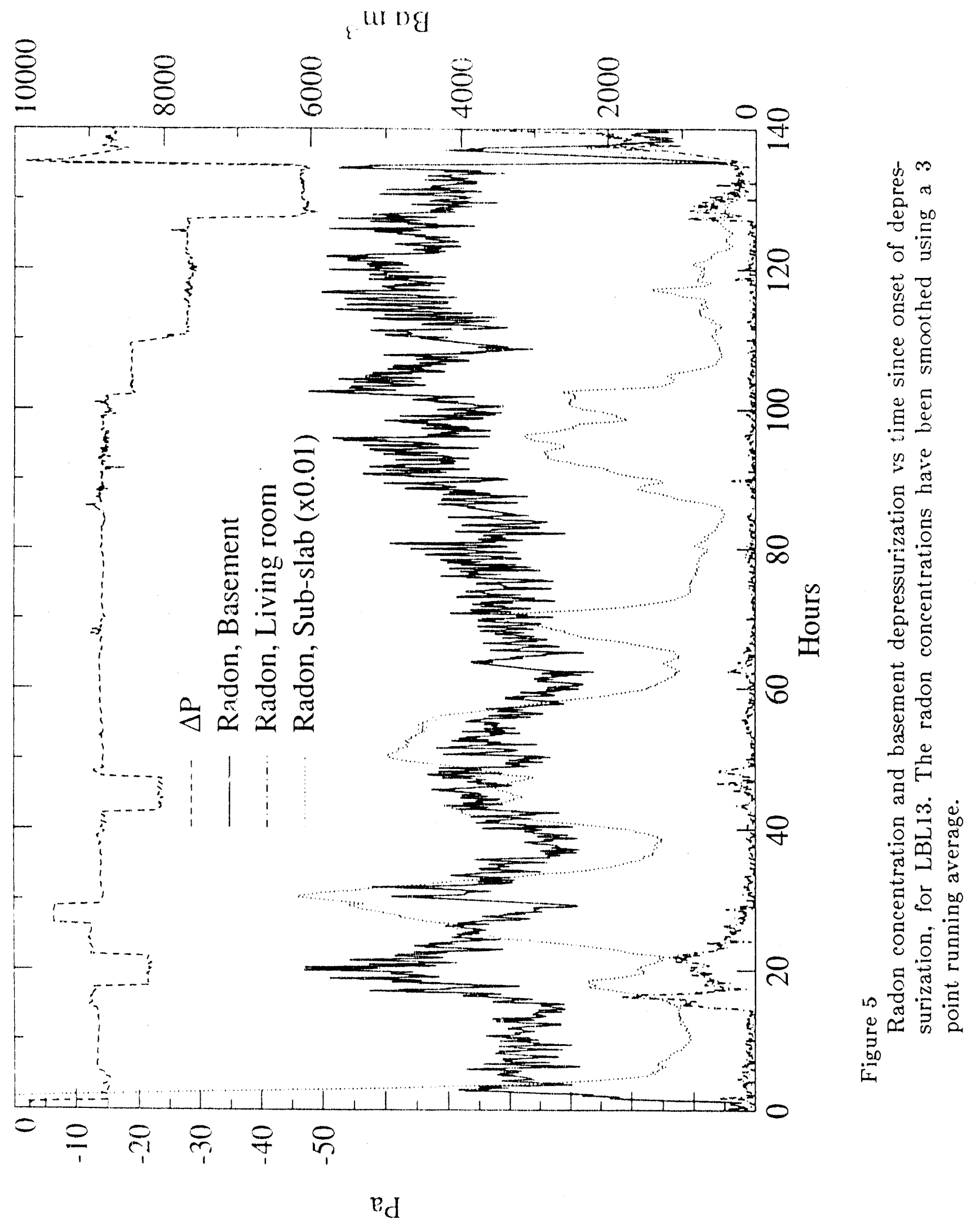




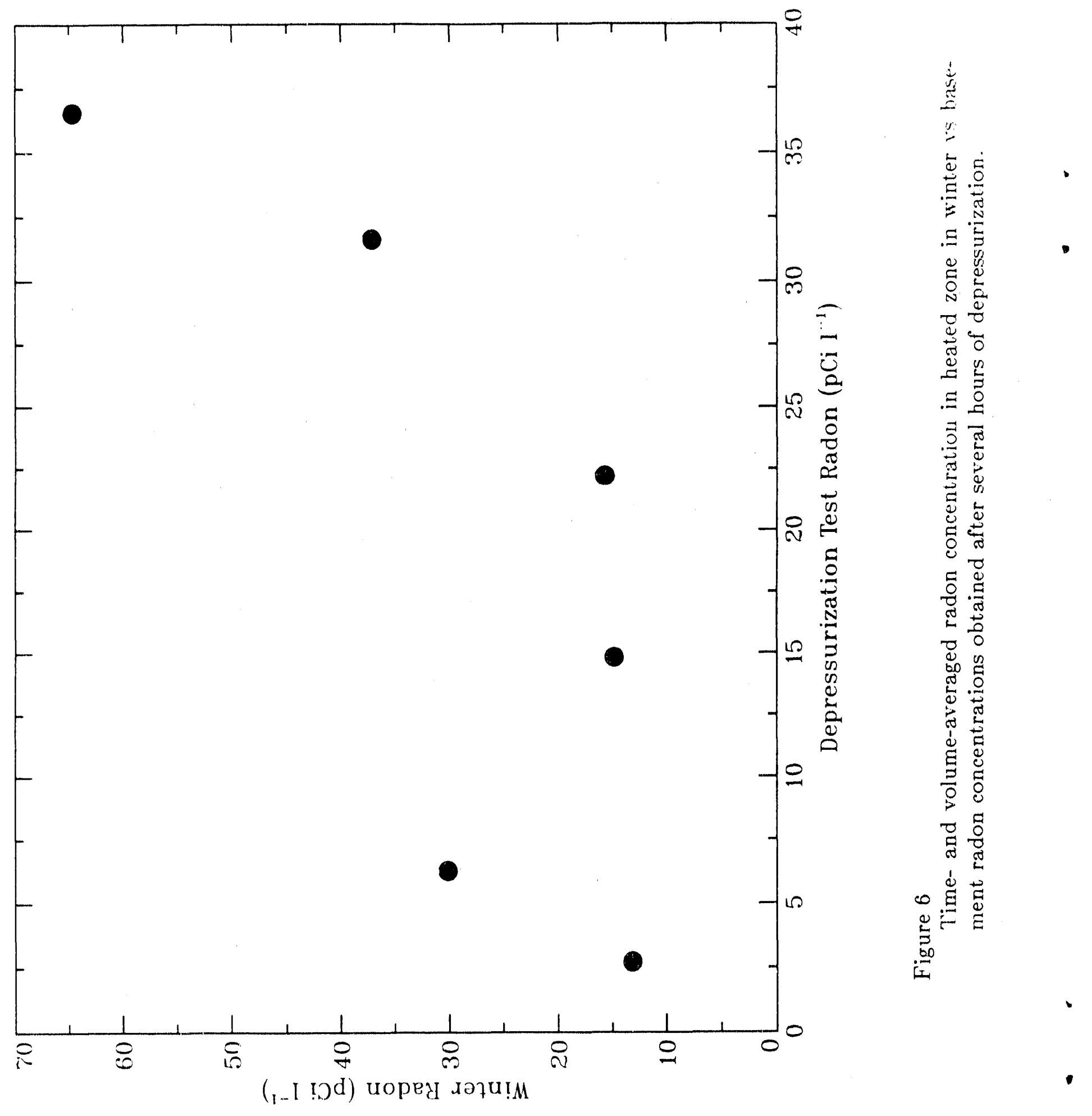




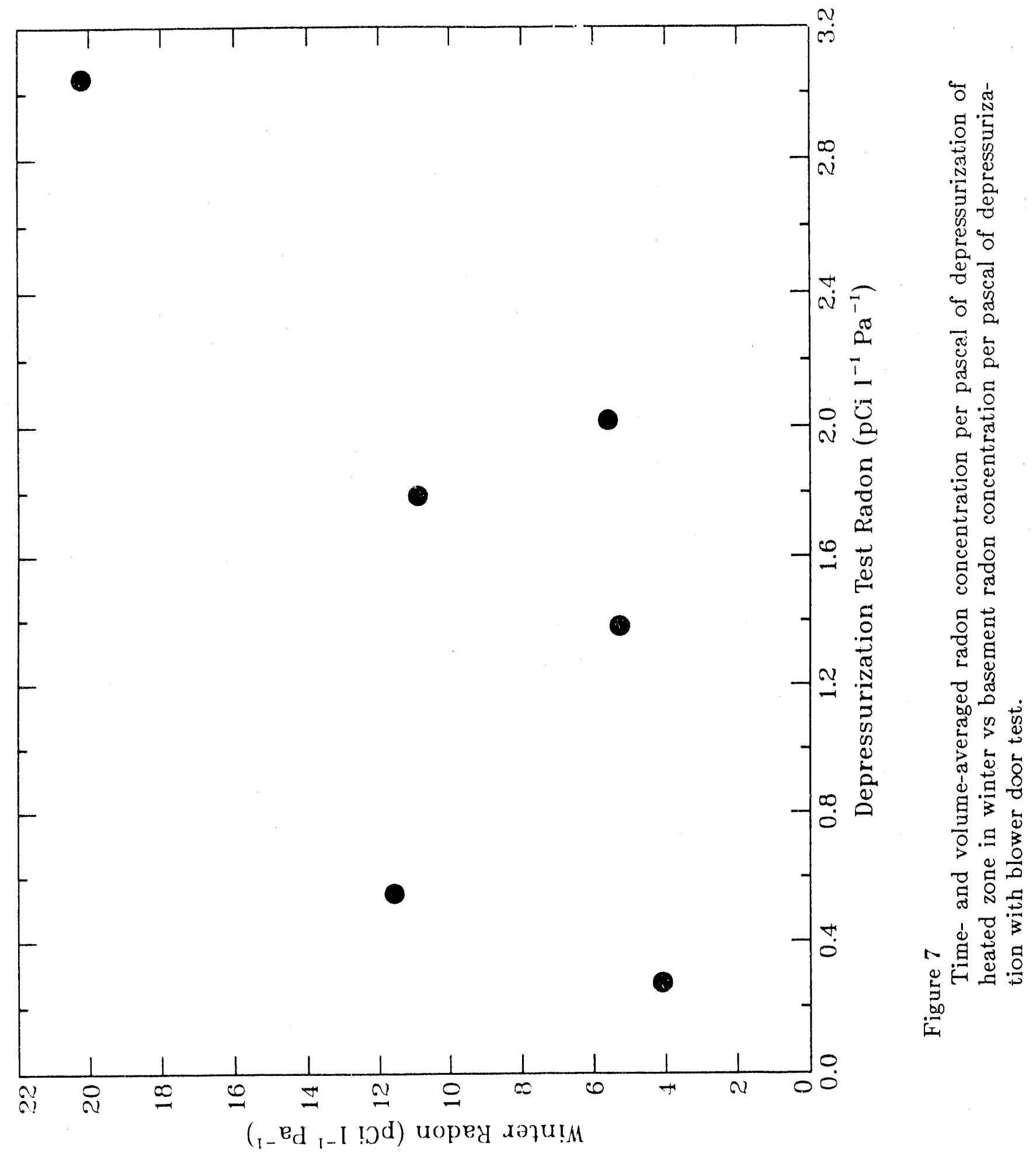



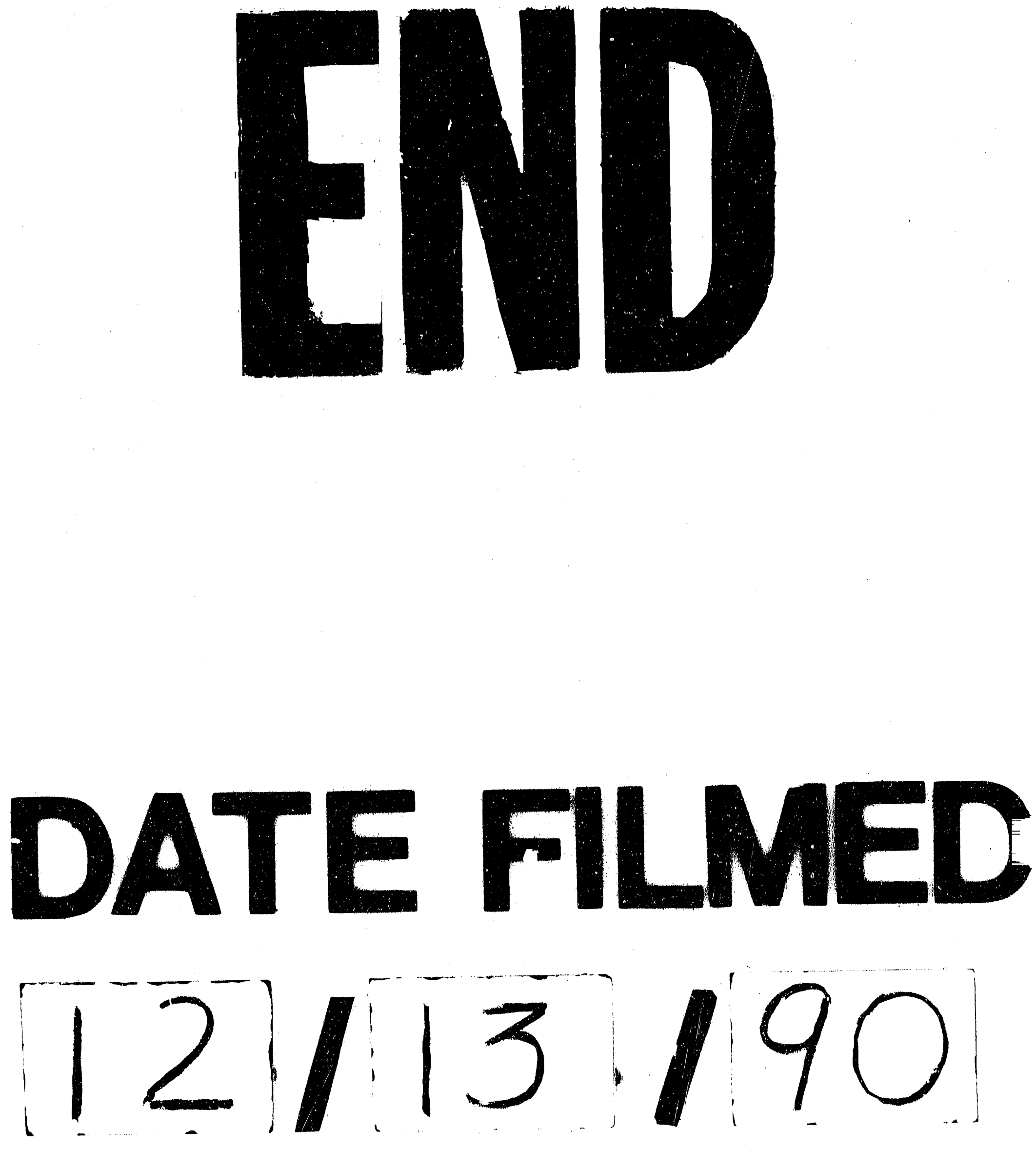
